\title{
INDIVIDUAL AND COUPLE TASTES FOR CHILDREN: THEORETICAL, METHODOLOGICAL, AND EMPIRICAL ISSUES
}

\author{
Richard P. BAGOZZI * \\ University of Michigan, Ann Arbor, USA \\ M. Frances Van LOO \\ University of California, Berkeley, USA
}

Received January 28, 1986; accepted September 8, 1986

\begin{abstract}
A comparison is made between two alternatives for explaining family size decisions: a psychological model based on the individual needs of the spouses and a social psychological model based on the husband-wife relationship. By use of higher order factors within the context of structural equation models, it is shown that the two approaches can be derived as special cases of a single, integrative framework. In this way, a theory is developed and tested which explicitly represents the family-size decision process as both an individual and joint experience of the spouses.
\end{abstract}

\section{Introduction}

From a metatheoretical perspective, one may identify two alternative paradigms for the explanation of family size decisions: outcome thesies and process theories. In the former, family size is modeled as a response to more-or-less exogenous forces. For example, sociological theories hypothesize that family size is a social response to norms or other societal pressures, and economic theories maintain that family size is determined by income, price, or other economic factors. Process theories, in contrast, attempt to explicitly represent the intra-individual

* The ordering of names was determined by chance as both authors shared equally in the research.

Special thanks go to the reviewers for comments made on an earlier version of this article.

Requests for reprints should be sent to R.P. Bagozzi, University of Michigan, School of Business Administration, Ann Arbor, MI 48109-1234, USA. 
and/or interpersonal activities that function as antecedents to family choice decisions. For instance, psychological theories examine the attitudes of family members toward children, and social psychological theories investigate role relationships, power, or exchange processes between husband and wife.

A central issue underlying both outcome and process theories is the proper unit of analysis. Outcome theories have typically been formulated at the level of the household or family unit. Nevertheless, most tests of economic theories (e.g., Bagozzi and Van Loo 1982; Fleisher and Rhodes 1979; Willis 1973) and sociological theories (e.g., Bagozzi and Van Loo 1978; Smith-Lovin and Tickamyer 1978; Waite and Stolzenberg 1976) have relied on the responses of only a single spouse, usually the wife. The assumption is that one spouse will be a valid reporter of the characteristics of the household. To the extent that a respondent is unsure or for some other reason misreports information related to the measured independent variables predicting family size outcomes, random error will exist and may adversely affect parameter estimates. Moreover, if a respondent forgets, disagrees with a spouse, or deliberately misrepresents information, systematic error in the form of oinitted variables or inclusion of irrelevant prediciors may lead to false inferences. Even if one assumes that valid and reliable information has been provided at the household level, outcome theories beg the question as to the processes leading to family size choices. Because these can occur a.eferentially across families, depending on the individual tastes of family members and the balance of power or egalitarianism in decision making, it is likely that outcome theories will invariably lead to lower levels of explained variance than approaches actually representing the interpersonal processes leading to choices.

Process theories thus, in principle, offer an advantage. However, two alternative approaches have been used to formulate the unit of analysis in process theories. In the first approach, individual beliefs (e.g., judgments) and feelings (e.g., motivation, attitudes) of both the husband and wife are taken as the unit of analysis. Because these are used to explain outcomes at the family level (e.g., joint decisions or actual births), the approach implicitly assumes that either social processes do not play a determinative role or else if they do they can be reduced to the psychological responses of individuals. Many studiss have taken such a perspective (e.g., Beckman 1978, 1979; Davidson and Jaccard 1975; Vinokur-Kaplan 1978). But only two could be found that used 
information from botn hisband and wife in their empirical tests (Beckman et al. 1983; Thomson 1983), thus avoiding the measurement and conceptual problems noted heretofore with respect to outcome theories.

A much less studied approach to process theories takes the husband and wife relationship as the unit of analysis. In so doing, the objective is to avoid the philosophical pitfalls inherent in psychological reductionism (e.g., Webster 1973) and reification (e.g., Keat and Urry 1983). Bagozai and Van Loo $(1978,1980)$ propose such a theory at the level of the husband and wife relationship:

-...the theory views fertility decisions as an outcome of social psychological processes within the family. The attitudes, personality, and interpersonal orientations of the husband and wife are seen as interacting with their social exchanges. The nature of these exchanges is represented by the degree of role egalitarianism and social influence between husband and wife. Social and economic variables are then viewed as constraints on the husband's and wife's attitudes and their social exchanges.' (Bagozzi and Van Loo 1980: 93)

Although the theory is consistent with recent developments in interactionism (Harrè and Secord 1973) and the philosophy of science (Manicas and Secord 1983), it was tested originally using either the responses of the wife (Bagozzi and Van Loo 1978) or an average of both the husband's and wife's responses (Bagozzi and Van Loo 1980). The former exhibits the shortcomings noted heretofore, whereas the latter assumes that the husband and wife provide information in equal piuportions and without measurement error. Van Loo and Bagozzi (1984) recently overcame the shortcomings of these studies by examining the responses of both husband and wife in a key informant context.

The purpose of the present study is to develop the conceptual bases for the two types of process theories (hereafter termed the individual and interaction models, respectively) and to provide a test of both on the same set of data. Because the research builds upon the only previous attempt to compare the two models, the paper will begin with an analysis of the study performed by Thomson (1983). Next, key theoretical, methodclogical, and empirical issues will be addressed. Following this, the data and method will be described. Finally, the results and their interpretation will be presented. We have chosen to perform our empirical analyses on the same data used by Thomson (1983) in order tc provide as meaningful a test of the competing models as possible. 


\section{Thomson's study}

In an innovative and important study, Thomson (1983) compared a 'couple model', where the husband's and wife's responses were used as indicators of an overall family-based representation, to a 'wife-husband model', where the spouse's responses were represented as separate determinants of the couple's expectations for another child. It was found that the couple model had to be rejected whereas the wife-husband model, given certain corrections for methodological biases, was not rejected on a sample of $\mathbf{3 1 1}$ families. Thomson concluded, 'it would appear that models of fertility decisions and behavior based on the assumption that wife and husband share the utility of their children are misspecified' (1983: 517). This is an important study, not only because it is the first to test both the individual level and interaction models, but because it uses a methodology that explicitly takes into account measurement error, thereby enhancing the chance that true causal relationships would be discovered had they existed.

Jr the following reasons, however, it is maintained herein that Thomson's (1983) fincings should be viewed with caution and the conclusions regarded as inconclusive. First, the couple model that was tested may have been und -ly restrictive. In that model (see fig. 1, Thomson 1983: 509), two separate uti'ity constructs for the couple were formed (i.e., economic and emotio al utility), each measis'ed with three responses of the wife and three rec jonses of the husband. This assumes that (1) the couple's economic unitity of another child and the couple's emotional utility of anothe child are unidimensional constructs, and (2) both the husbanc'3 and wife's responses agree to the same extent (within the bounds of random error) on each dimension. If either or both the couple's economic utility or emotional utility are multidimensional and/or the husband and wife weigh the elements of each utility differentially, then Thomson's couple model should be rejected. But notice that rejection of her model does noi previude the possibility that the spouses share similar utilities in a multidimensional sense and/or reach a mutual understanding based on differential weighting of the criteria comprising each utility. The former might occur when the range of content for each type of utility covers issues of varied importance (across issues) for the spouses. The latter would be likely when the spouses interact to reach a mutual accommodation with respect to a particular family decision, yet retain differential interests or reflect 
differential contributions to that decision. This would result in a differential weighting across spouses. Thomson's couple model does not permit such occurrences but rather presumes that both spouses value each element of both utilities equally and in a unidimensional sense.

A second issue concerns Thomson's wife-husband model. In this model, couple's expectations for another child were represented as a function of four constructs: wife's economic utility, husband's economic utility, wife's emotional utility, and husband's emotional utility of another child. Each construct was operationalized by three items responded to by the wife or husband, depending on the respective construct. Ostensibly, the wife-husband model is intended to represent the utility of another child as 'an individual experience of wife and of husband rather than a shared experience of the couple' (Thomson 1983: 517). Although this model, too, was rejected on the basis of a goodness-of-fit test, Thomson was able eventually to achieve an acceptable fit by allowing correlated errors to occur between measures across and within constructs.

It is maintained herein that the wife-husband model and accompanying findings do not support the intended test and conclusions on a number of grounds. First, it should be noted that, although the overall goodness-of-fit was acceptable, two of the four key parameters in the wife-husband model were contrary to theory and predictions. That is, wife's economic utility was found not to significantly predict couple's expectations of another child, while husband's economic utility was found to significantly predict couple's expectations but in a negative way, opposite to theory.

Second, and more importantly, it is not clear that the wife-husband model with correlated errors is a meaningful model. At a minimum, the interpretation of the model is ambiguous because of the implications of correlated errors. Each correlated error suggests that one or more omitted variables are at work. Unfortunately, the origin and nature of the omitted variable(s) must remain speculative, since no independent measurements of possible contaminants were taken.

Moreover, as the number of correlated errors increase in relation to the number of hypothesized factors and measurements actually obtained, the substantive meaning of the null model is altered. This problem is analogous to the issue of over-fitting factors to measures in common exploratory factor analysis. Although no firm guidelines exist as to what constitutes appropriate justification for correlated errors, it 
is suggested that at least three criteria must be satisfied: (1) a theoretical and/or methodological reason should exist for any correlated errors, (2) the number of correlated errors should be small in relation to the number of hypothesized factors and measurements, and (3) the magnitude of correlated errors should be small (Bagozzi 1984). The latter is necessary in order to ensure that sufficient explained variance in measurements is due to hypothesized factors and not to omitted variables.

In Thomson's (1983) study, the first criterion is satisfied for the correlated errors between husband's and wife's responses to the independent variables if one grants that such effects represent the idiosyncratic and questionnaire biases noted by the author. However, it is unclear why these only occur between husband's and wife's responses to the utility items specific to either the economic or emotional factors. If the biases were valid, one would normally expect correlated errors both among measures within factors and across measures across factors, irrespective of the respondent type. However, such allowances drastically change the null hypothesis model and make interpretation of the findings tenuous at best. In addition, no justification was provided for the correlated errors between measures of independent and dependent variables. The omitted variable(s) implied here could inflate or suppress the key parameter estimates of the study. The second criterion is not satisfied, as at least 7 (and possibly as many as 18) correlated errors were permitted; yet the null model hypothesizes only 5 factors indicated by a total of 14 measurements. Thomson is unclear as to how many correlated errors were estimated. Finally, it is not possible to evaluate the third criterion because Thomson did not report the parameter estimates for correlated errors.

Still another problem with the wife-husband model is the presence cf multicollinearity among predictors. The magnitude of correlations among independent variables was significantly greater than the magnitude of correlations between independent and dependent variables in a number of incidences (see Thomson 1983: 512). This adversely affects the precision of parameter estimates representing the effects of husband and wife utility on child expectations. Mílticollinearity is most likely the reason why wife's economic utility did not significantly predict expectations and husband's economic utility actually was inversely related to expectations. We will proviće more formal results of multicollinearity and one remedy in the añalyses presented hereafter. 
A final limitation of the study arises from the questionnaire items. Because these were constructed as two-point and three-point indices, it is possible that the multivariate normality assumption necessary for the maximum likelihood procedures was not met. Violation of the assumption tends to suppress correlations and inflate the chi-square goodnessof-fit measure for any model. Further, if kurtosis is excessive, it is possible that the goodness-of-fit measure may be underestimated. As a consequence, some danger exists for type I and type II errors.

\section{Three central concerns}

\section{Theoretical issues}

Individual level and interaction theories rest on fundamentally different assumptions. Consider first the logic of individual level theories. Household decisions or outcomes are hypothesized to be determined by the individual tastes or utilities (i.e., psychological reactions) of husband and wife. Societal, economic, or background factors (e.g., education, age at marriage, parent's occupation) are believed to work through psychological variables of the husband and wife, which, in turn, are thought to be the proximal causes of family choices. Fig. 1 depicts the general form for many individual level theories (e.g., Beckman et al. 1983; Fishbein 1972).

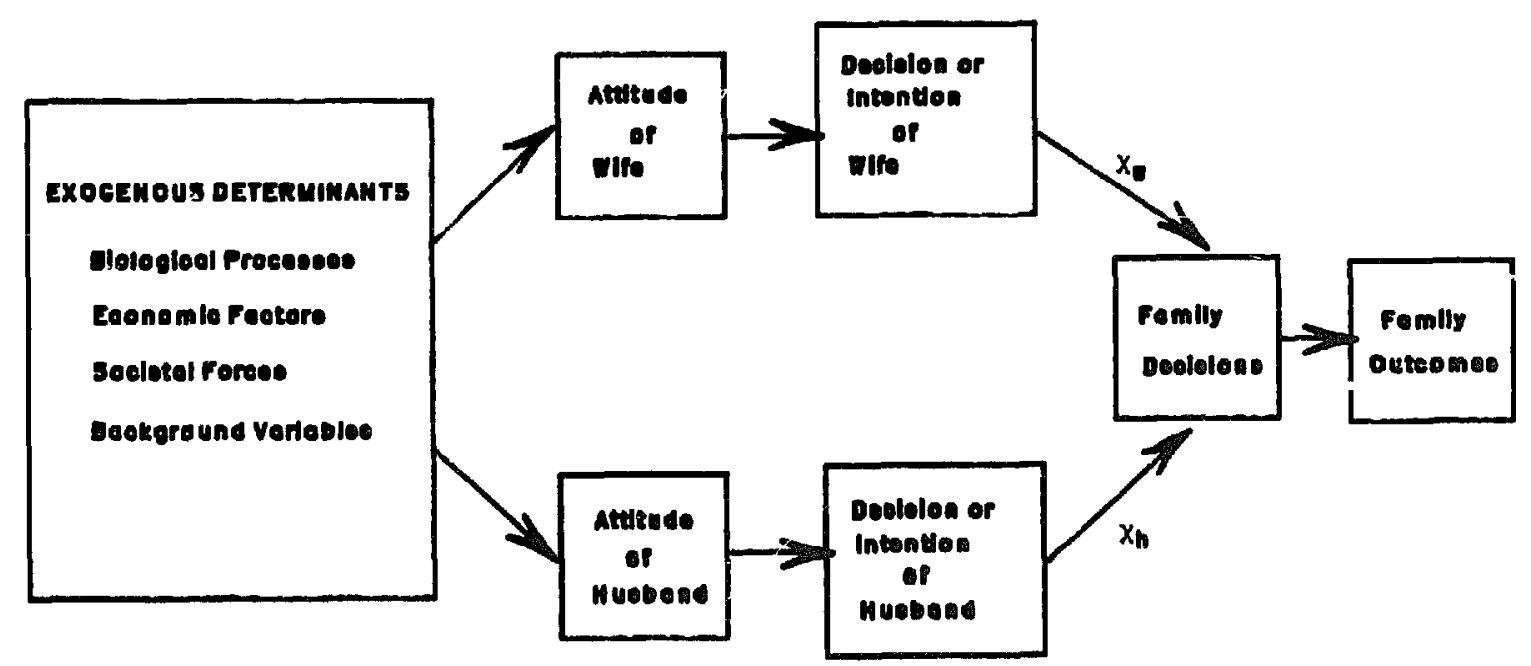

Fig. 1. Outline of determinants and processes for individual level theories. 
The strength of individual level theories lies in their ability to specify the psychological factors influencing family choices and outcomes. Indeed, the individual-based causes leading to household decisions and outcomes are explicitly represented.

Notice, however, that individual level theories mix variables across levels of analysis. Constructs formed at the psychological level are used to explain variation in constructs formed at the group level. Also, although individual level theories capture the effects of influence from husband and frôii wife, they do not model the actual interaction processes between the spouses. Rather, the social processes are presumed to operate in a homogenous way across households. Further, the mechanisms whereby individual attitudes, decisions, or intentions of husband and of wife are integrated and taken into account to produce a mutual decision and/or determine shared outcomes are left implicit. No theory is specified for how a joint outcome is caused by the separate influences of husband and wife. That is, the rationale and processes underlying paths $X_{w}$ and $X_{h}$ in fig. 1 are not specified. Individual level theories assume that joint decisions or outcomes are simply a weighted average of the psychological reactions of the spouses. Intervening social processes, if any, are ignored.

Consider next the rationale for the interaction theory. Here the effects of social interactions between the spouses are modeled as the causes of family decisions and related behavioral outcomes. Because group or social constructs such as role egalitarianism are used to explain group constructs such as shared decisions, the conceptual problem of spanning levels of analysis is avoided. Fig. 2 illustrates the general structure of interaction theories (e.g., Bagozzi and Van Loo 1978, 1980; Beckman et al. 1983; Hollerbach 1980; Van Loo and Bagozzi 1984). The central hypotheses lie within the social interaction $\rightarrow$ family decision $\rightarrow$ family outcome sequence. It is maintained that the individual needs and desires of the spouses are resolved through interaction processes (e.g., social exchange, give-and-take, mutual decision making, negotiation, social influence), and these, in turn, serve as the proximal causes of family choices and subsequent outcomes. The spouses may, but need not, share or fully agree on a decision outcome. Indeed, because of conflicts of interest, imbalances in roles, or power disparities, one spouse may have a dominant say in the process. Interaction theories attempt to explicitly model social processes within the family, ranging from egalitarian or balanced relationships to one- 


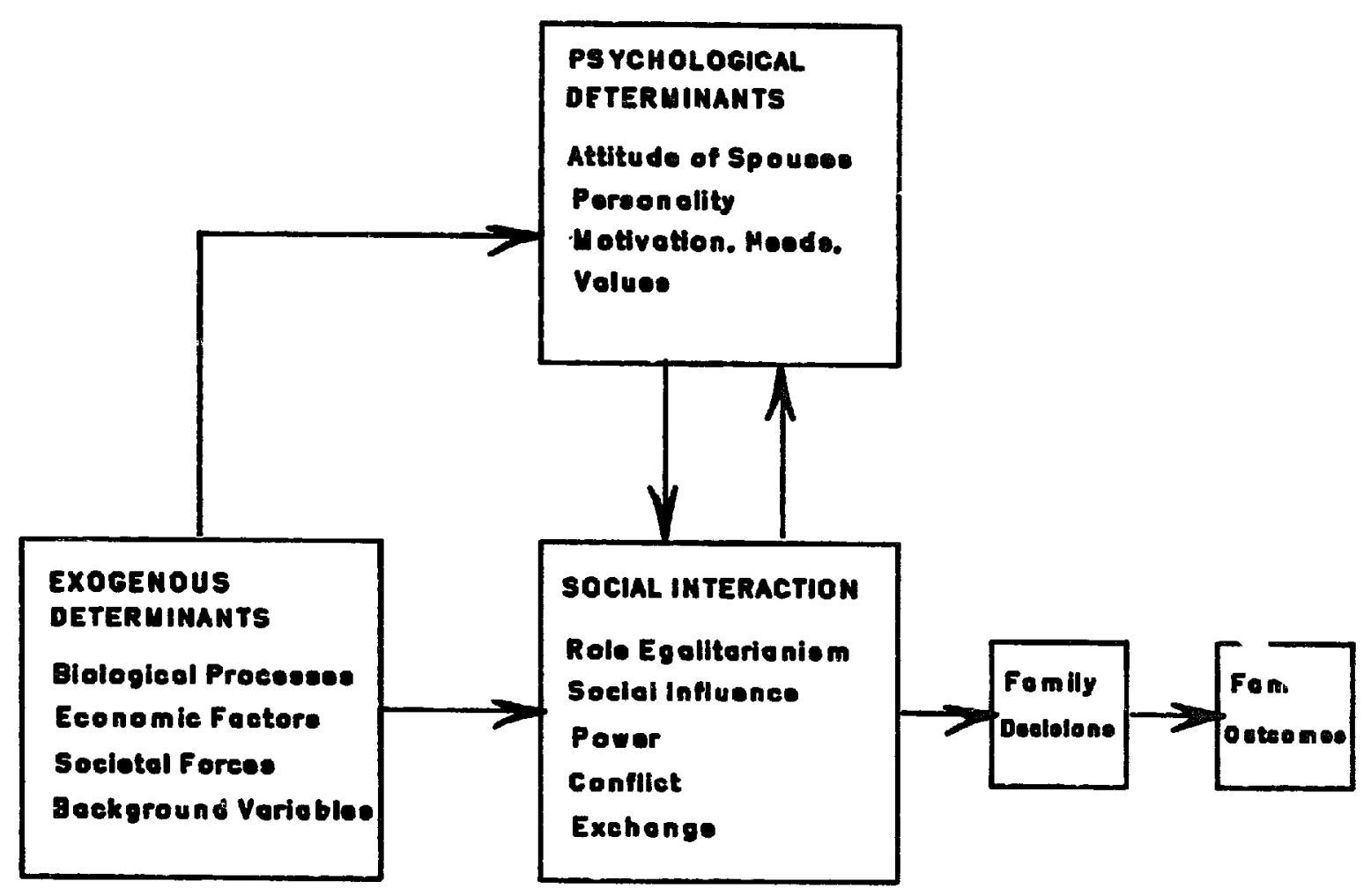

Fig. 2. Outline of determinants and processes for interaction theories.

sided situations, and to specify how these processes influence joint decisions and family outcomes.

Notice, however, that interaction theories do not, or at least have not to date, specified how the individual psychological reactions of the spouses influence the social processes between them. Rather, only the effects of the individual contributions of the spouses are modeled, and psychological consequences receive only indirect attention (e.g., as measures of family constructs). We could have used dashed arrows in fig. 2 to point to this underdeveloped aspect of interaction theories.

A theory is lacking that integrates the desirable characteristics of both the individual level and interaction approaches in one overall framework. That is, a theory is needed specifying how the psychological attributes of the spouses influence the social interactions leading to family decisions and outcomes. In the Method section presented later in the paper, we attempt to develop a model that does just this while at the same time permitting a decomposition of effects into separate individual level and interaction contributions if desired. 


\section{Methodological issues}

An important consideration concerns how social constructs should be measured. At least three alternatives deserve attention.

In the first, the responses of husband and wife are simply averaged to form a measure of a couple construct. This procedure is a common one in sociology, but it has two drawbacks. First, if based on the psychological reactions of the spouses, the significance of the average is unclear in a substantive sense. For example, if one were to average the attitudes of husband and wife toward contraceptives, would this validly represent the attitude of the family? The meaning of a 'family attitude' is unclear, as social or group variables are hypothetical constructs with no natural life of their own. Second, even allowing that an average validly reflects a property of a social entity, it is likely that the operation will introduce measurement error and at the same time obscure the relative contribution of husband and wife to the measure.

A second and more preferred way to operationalize group or social constructs is to retain the unique information provided by the spouses and use their responses as indicators of the variables of interest. Thomson (1983) used this procedure in her research with the aid of structural equation models and latent variables. The approach not only permits one to identify the relative contributions of spouses in the measurement of constructs, but it provides explicit measia es of random error. It should be noted, however, that the procedures presuppose that the social constructs are meaningful and that individual responses constitute valid measures. In Thomson's (1983) and the present study, it is assumed that the couple's economic and emotional tastes and the couple's expectations for another child exist. However, no tests of the construct validity of these group entities can be made, given data limitations. Construct validation is, in part, a metaphysical issue, and tests such as the multitrait-multimethod matrix approach (e.g., Campbell and Fiske 1959) adäress only the empirical implications of the constructs and require multiple measures by multiple methods.

The third approach to the measurement of social or group constructs is to utilize the key informant methodology (e.g., Seidler 1974). Here family members or other outside observers provide direct assessments of the social structure or processes going on within the family. Rather than supplying information on one's own internal states, the informant makes a judgment as to the characteristics of an external entity. For 
example, spouses might be asked to evaluate the normative structure, roles, or decision-making processes in the family. The individual evaluations could then be used as indicators of a family construct by use of the structural equation methodology and latent variables. If one treats separate informants of social constructs as multiple methods, then it is possible to ascertain construct validity in addition to representing the contributions of individual spouses and taking into account measurement error. Van Loo and Bagozzi (1984) used the key informant methodology in their study of family size and wife's labor force behaviors.

Because of data limitations, the present study will employ the second methodology noted above. In addition, higher order latent variables will be employed to overcome the multicollinearity problems found in Thomson's (1983) study (see Method).

\section{Empirical issues}

When dealing with psychological responses and social constructs, it is likely that measurement error will become a concern. Measurement error has the effect of suppressing the observed relationships among variables. That is, measures of association such as the correlation coefficient or regression parameter will reflect both the forces producing covariation and random error.

A second empirical issue concerns the chi-square goodness-of-fit test accompanying most structural equation analyses by the method of maximum likelihood. Because the chi-square measure is directly proportional to sample size, it sometimes leads to problems in interpretation as the sample size increases. Therefore, it would be desirable to employ additional measures that are not functions of sample size when evaluating any model. In this regard, Bentler and Bonett's (1980) incremental fit index will be used herein along with the chi-square test.

\section{Method}

\section{Model specification}

Figs. 3 and 4 present the models tested in this resuarch. In fig. 3, it is hypothesized that the couple's expectations for another child are a 


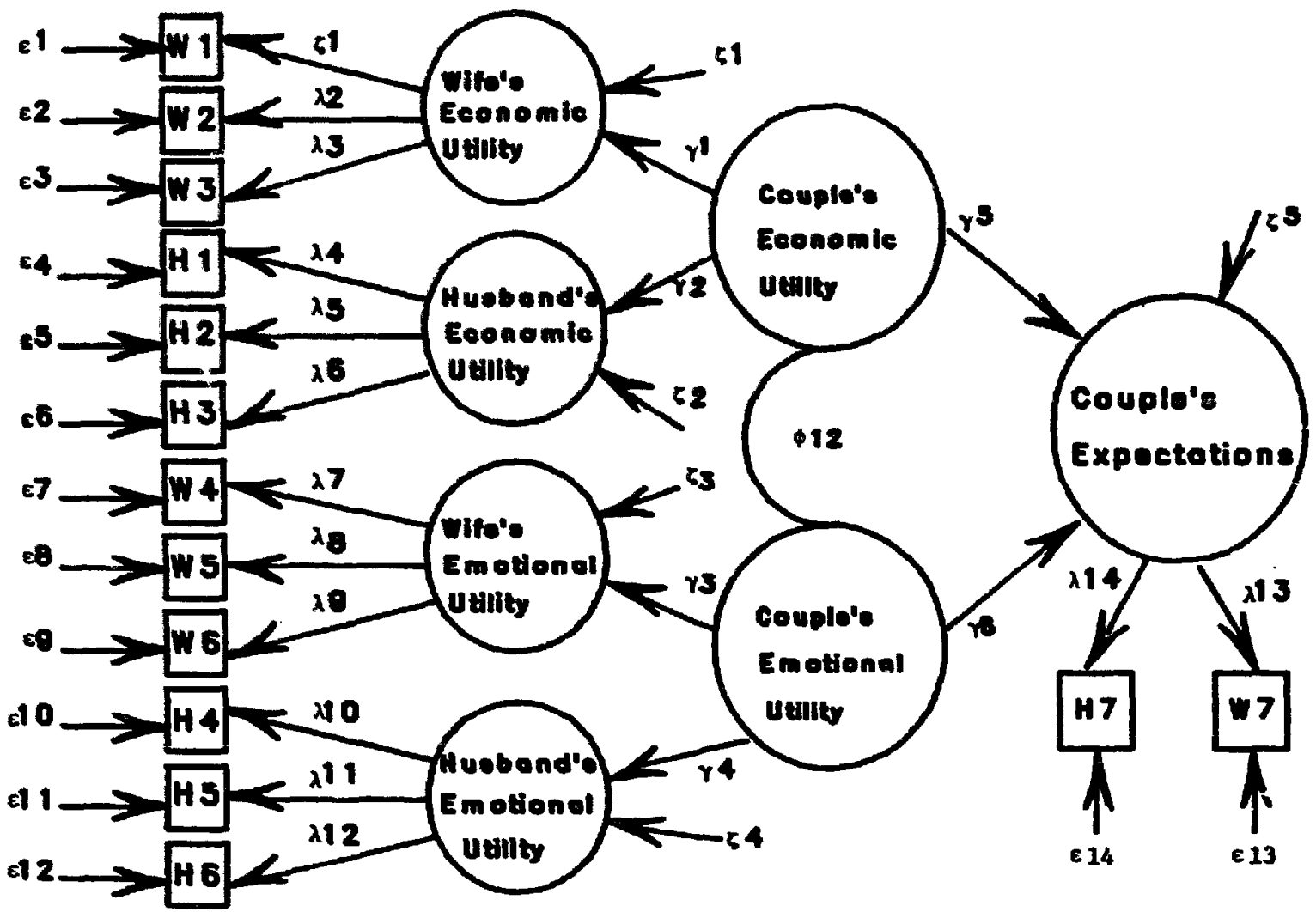

Fig. 3. Specification of model hypothesizing separate couple economic and couple emotional utilities for another child.

direct function of two family-unit constructs: coupie's economic utility of another child and couple's emotional utility of ancther child. The family-unit constructs, in turn, are indicated by separate wife and husband economic and emotional utilities, respectively. In addition to providing a test for the impact of the two family-unit constructs on child expectations, the model of fig. 3 permits a test of the uniqueness (i.e., discriminant validity) of the two constructs. This can be assessed with an examination of $\phi_{12}$ to see if twice its standard error includes 1.00. If the two family-unit constructs do not exhibit discriminant validity, then a single couple construct will be tested as shown in fig. 4 . The model of fig. 4 hypothesizes that the couple has an overall utility for children which is the proximal cause of the couple's joint expectations for another child. The overall utility, in turn, is a function of or reflected in the individual spouse's economic and emotional utilities. In this way, individual utilities map into couple utilities in route to determining joint choices.

The models shown in figs. 3 and 4 are higher order structural equation models and exhibit a number of beneficial properties (see, 


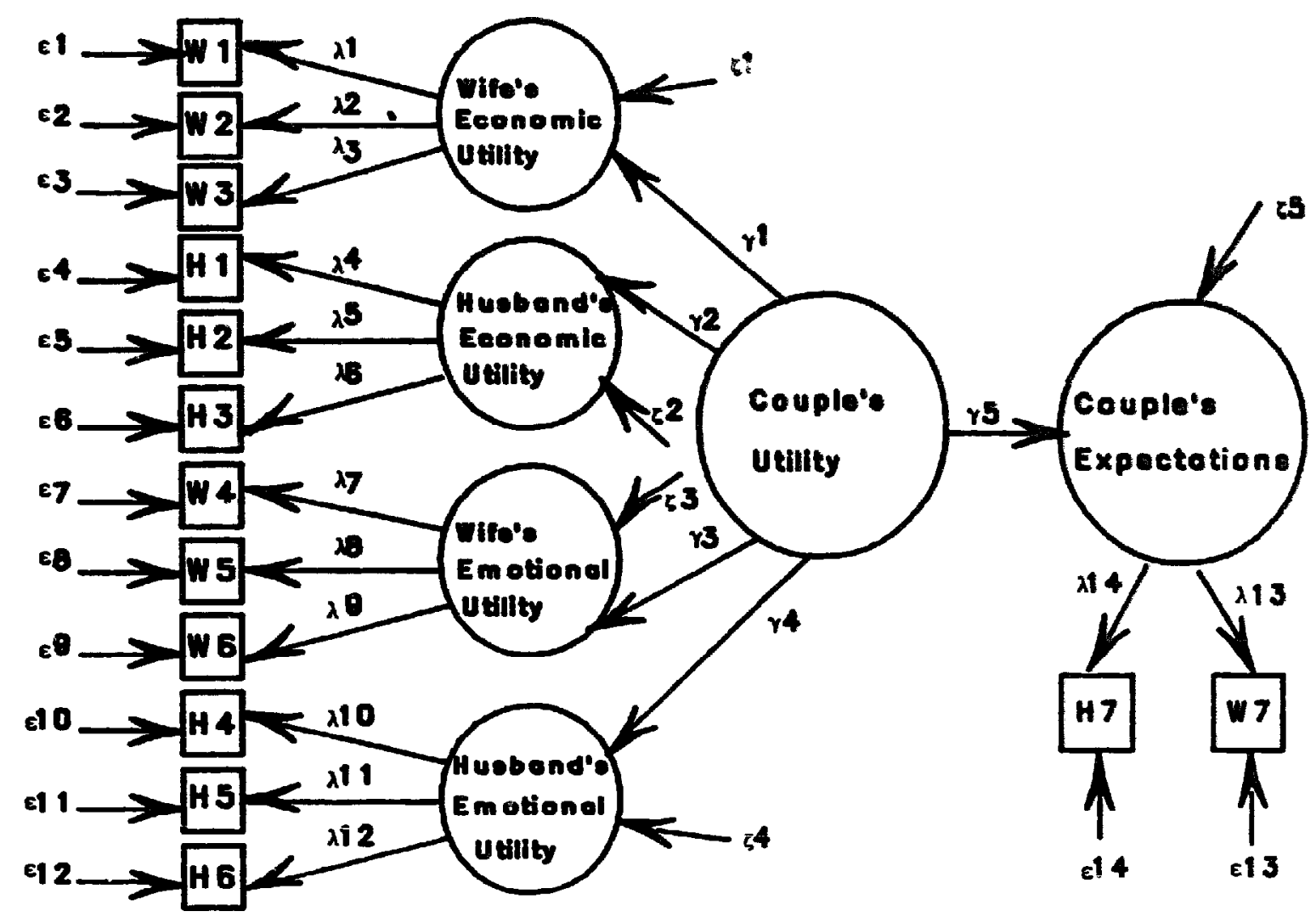

Fig. 4. Specification of model hypothesizing single underlying couple utility for another child.

e.g., Bagozzi 1985: 55-57). First, from a conceptual standpoint, the models represent both the individual spouse's tastes and their shared desires. It should be stressed that the representation of shared desires does not assume that the spouses agree entirely or have equal influence on family decisions and outcomes. Rather, each spouse is allowed to contribute differentially to the couple construct, depending on his or her relative utilities. The parameters $\gamma_{1}-\gamma_{4}$ in figs. 3 and 4 capture the relative contribution of each spouse to the couple constructs for each type of utility. Similarly, the relative influence of each spouse on couple expectations for another child can be represented as follows: (1) for the model of fig. 3: $\gamma_{1} \gamma_{5}$ and $\gamma_{2} \gamma_{5}$ give the relative effects of wife's and husband's economic utility on expectations, respectively; and $\gamma_{3} \gamma_{6}$ and $\gamma_{4} \gamma_{6}$ yield the relative effects of wife's and husband's emotional utility on expectations, respectively, and (2) for the model of fig. 4: $\gamma_{1} \gamma_{5}, \gamma_{2} \gamma_{5}$, $\gamma_{3} \gamma_{5}$, and $\gamma_{4} \gamma_{5}$ reveal the relative impact of wife's economic, husband's economic, wife's emotional, and husband's emotional utility on expectations, respectively.

A second benefit of the models of figs. 3 and 4 lies in the partition- 
ing of variance of observations into three useful components. To see this, one may proceed as follows. The equations for the first-order factors in fig. 3 may be written as

$$
\left[\begin{array}{l}
F_{1} \\
F_{2} \\
F_{3} \\
F_{4} \\
F_{5}
\end{array}\right]=\left[\begin{array}{cc}
\gamma_{1} & 0 \\
\gamma_{2} & 0 \\
0 & \gamma_{3} \\
0 & \gamma_{4} \\
\gamma_{5} & \gamma_{6}
\end{array}\right]\left[\begin{array}{l}
F_{1}^{*} \\
F_{2}^{*}
\end{array}\right]+\left[\begin{array}{l}
\zeta_{1} \\
\zeta_{2} \\
\zeta_{3} \\
\zeta_{4} \\
\zeta_{5}
\end{array}\right],
$$

where the $F_{i}$ are the first-order factors corresponding to the individual spouse's utilities (except for $F_{5}$ which is the factor for couple's expectations), the $F_{j}^{*}$ represent the shared components of variance among the respective $F_{i}$, the $\gamma_{i}$ reflect the relative contribution of each $F_{i}$ to its respective $F_{j}^{*}$, and the $\zeta_{i}$ depict the unique components of the $F_{i}$. One may write the measurement equations as

$\left[\begin{array}{l}W_{1} \\ W_{2} \\ W_{3} \\ H_{1} \\ H_{2} \\ H_{3} \\ W_{4} \\ W_{5} \\ W_{\epsilon} \\ H_{4} \\ H_{5} \\ H_{6} \\ W_{7} \\ H_{7}\end{array}\right]=\left[\begin{array}{ccccc}\lambda_{1} & 0 & 0 & 0 & 0 \\ \lambda_{2} & 0 & 0 & 0 & 0 \\ \lambda_{3} & 0 & 0 & 0 & 0 \\ 0 & \lambda_{4} & 0 & 0 & 0 \\ 0 & \lambda_{5} & 0 & 0 & 0 \\ 0 & \lambda_{6} & 0 & 0 & 0 \\ 0 & 0 & \lambda_{7} & 0 & 0 \\ 0 & 0 & \lambda_{8} & 0 & 0 \\ 0 & 0 & \lambda_{9} & 0 & 0 \\ 0 & 0 & 0 & \lambda_{10} & 0 \\ 0 & 0 & 0 & \lambda_{11} & 0 \\ 0 & 0 & 0 & \lambda_{12} & 0 \\ 0 & 0 & 0 & 0 & \lambda_{13} \\ 0 & 0 & 0 & 0 & \lambda_{14}\end{array}\right]\left[\begin{array}{l}F_{1} \\ F_{2} \\ F_{3} \\ F_{4} \\ F_{5}\end{array}\right]+\left[\begin{array}{l}\varepsilon_{1} \\ \varepsilon_{3} \\ \varepsilon_{3} \\ \varepsilon_{4} \\ \varepsilon_{5} \\ \varepsilon_{6} \\ \varepsilon_{7} \\ \varepsilon_{8} \\ \varepsilon_{9} \\ \varepsilon_{10} \\ \varepsilon_{11} \\ \varepsilon_{12} \\ \varepsilon_{13} \\ \varepsilon_{14}\end{array}\right]$,

where the symbols are as defined above and in fig. 3. Substitution of eq. (2) into eq. (1) yields:

$X=\Lambda\left(\gamma F^{*}+\zeta\right)+\varepsilon$, 
where $X=\left(W_{1}, W_{2}, W_{2}, W_{3}, H_{1}, H_{2}, H_{3}, W_{4}, W_{5}, W_{6}, H_{4}, H_{5}, H_{6}\right.$, $\left.W_{7}, H_{7}\right)$, and the remaining parameters correspond to the respective vectors cr matrices in eqs. (1) and (2). We can see now that each measurement contains variation due to (1) a second-order factor (i.e., a family-unit construct) common to all indicators of either economic or emotional utility, (2) a unique component common to indicators of only one first-order construct, and (3) random error (i.e., ह). Compare eq. (3) to the following equation proposed by Thomson (1983) which contains only first-order factors:

$\boldsymbol{X}=\boldsymbol{\Lambda F}+\boldsymbol{\varepsilon}$

Here we see that the model of eq. (4) might misleadingly confound components common to measurements across either economic or emotional utility as indicated by both spouses (i.e., $F_{1}^{*}$ or $F_{2}^{*}$ ) with components common to only measurements provided by a single spouse (i.e. either $F_{1}, F_{2}, F_{3}$, or $F_{4}$ ). The use of higher order factors permits the researcher th :pportunity to explicitly account for both classes of components as well as measurement error. In addition, the estimates of $\gamma_{5}$ and $\gamma_{6}$ in fig. 3 will be purged of random error. Similar properties apply to the model of fig. 4. Further, the model of fig. 4 completely removes the negative effects of multicollinearity among the $F_{i}$ since these now become indicators of the $F_{j}^{*}$ and only a single endogenous predictor of family expectations results.

\section{Data}

The data for this study are from the U.S. Value of Children Survey (e.g., Hoffman et al. 1978) and have been previously analyzed by Thomson (1983). A nationally representative sample of 1,569 women in the United States was taken in 1975. The sample response rate was 79\%. To qualify for inclusion in the survey, women had to be under 40 years of age and either legally married or having lived with a man for the previous six months or longer. From this sample, 576 women and their partners were contacted, since responses were needed from couples. A total of 438 couples yielded data, for a response rate of $76 \%$.

Because the theory tested in this study is based on expectations for 'another child', only those couples who had one or more children $(n=337)$ were included in the final sample selection. Of this group, 26 
Table 1

Variables examined in study and their measures.

\begin{tabular}{|c|c|}
\hline Variable & Measure \\
\hline $\begin{array}{l}\text { Economic utility of } \\
\text { another child }\end{array}$ & $\begin{array}{l}\text { Importance }(0=\text { not important, } 1=\text { somewhat important, } 2=\text { very } \\
\text { important }) \text { of following reasons for having another child: } \\
\text { 1. One more person to help the family } \\
\text { economically, } \\
\text { 2. have someone to help in old age, } \\
\text { 3. have a child to help around the house. }\end{array}$ \\
\hline $\begin{array}{l}\text { Emotional utility of } \\
\text { another child }\end{array}$ & $\begin{array}{l}\text { Importance }(0=\text { not important, } 1=\text { somewhat important, } 2=\text { very } \\
\text { important }) \text { of following reasons for having another child: } \\
\text { 1. someone to love and care for, } \\
\text { 2. feel needed and useful, } \\
\text { 3. being a parent is something you feel } \\
\text { you can do well. }\end{array}$ \\
\hline $\begin{array}{l}\text { Expectations for } \\
\text { another child }\end{array}$ & $\begin{array}{l}\text { Whether or not expected family size is greater than present family } \\
\text { size. }\end{array}$ \\
\hline
\end{tabular}

failed to give responses to all items, and the final sample size was thus $n=311$.

Table 1 presents the items used to measure the variables. Discussions of the rationale for these items and the effect of the utility for another child on expectations for another child can be founci in Hoffman and Hoffman (1973) and Thomson (1983). Bulatao (1976) presents empirical analyses using the items in a somewhat similar context.

\section{Statistical procedures}

The parameters and hypotheses implied by eqs. (1)-(3) were examined by use of the LISREL program (Jöreskog and Sörbom 1978). The LISREL program provides procedures for estimating and testing a wide range of linear models and is similar to standard multivariate statistical methods used by economists and others. It differs from traditional procedures primarily in its ability to separate and estimate errors in variables from errors in equations. It thus permits the researcher the opportunity to investigate theoretical hypotheses while correcting for the contaminating effects of measurement error.

Because the models tested herein contain higher order factors, it was necessary to use the LISREL IV program. This requires a reparameteri- 
zation along the lines shown in eqs. (1)-(3). The LISREL $V$ and LISREL VI programs available to the authors have anomalies and can not handle higher order factors.

Assessment of the goodness-of-fit of the models is done through two measures. First, the discrepancy between implied and observed variance-covariance matrices is assessed through a likelihnod ratio $\chi^{2}$ test. A $p$-value greater than $\mathbf{0 . 1 0}$ is considered a satisfactory fit (Jöreskog and Sörbom 1978). Second, because of the sensitivity of the $\chi^{2}$ test to sample size, Bentler and Bonett's (1980) incremental fit index, $\Delta$, is employed as an indicator of practical relevance and is independent of sample size. The incremental fit index ranges from zero to one, inclusive, with $\mathbf{0 . 9 0}$ or greater considered to be indicative of a satisiactory model.

Further discussions of the philosophical underpinnings of LISREL analyses can be found in Bagozzi (1980, 1984). Long (1983) presents an introduction to the statistical properties of the procedures.

\section{Results}

Table 2 summarizes the findings for the model of fig. 3. Notice first in the top of the table that all measurement parameters are statistically significant and random errors are low to moderate in magnitude. Next, although the overall chi-square goodness-of-fit measure $\left(\chi^{2}=110.1\right.$, $d f=70, p=0.002$ ) indicates that the model does not fully correspond to the data, the incremental fit index $(\Delta=0.91)$ suggests that the high chi-square value is in part due to sample size effects and that the model indeed captures a significant proportion of variance from a practical standpoint.

The first point to note with respect to the structural parameters (bottom of table 2) is that the husband contributes, on average, more to the couple economic utility construct than the wife, and the husband also contributes more to the couple emotional utility construct than the wife. This can be seen in comparisons of $\gamma_{1}=0.70$ to $\gamma_{2}=0.83$, and $\gamma_{3}=0.66$ to $\gamma_{4}=0.12$. Despite the differences in relative contributions, however, both spouses exhibit strong input to the couple constructs, with the husband accounting for about $19 \%$ more influence than the wife on economic utility and about $9 \%$ more influence on emotional utility. Notice next that the two parameters reflecting the effects of 
Table 2

Standardized parameter estimates, goodness-of-fit, and incremental fit measures for the model of fig. 3.

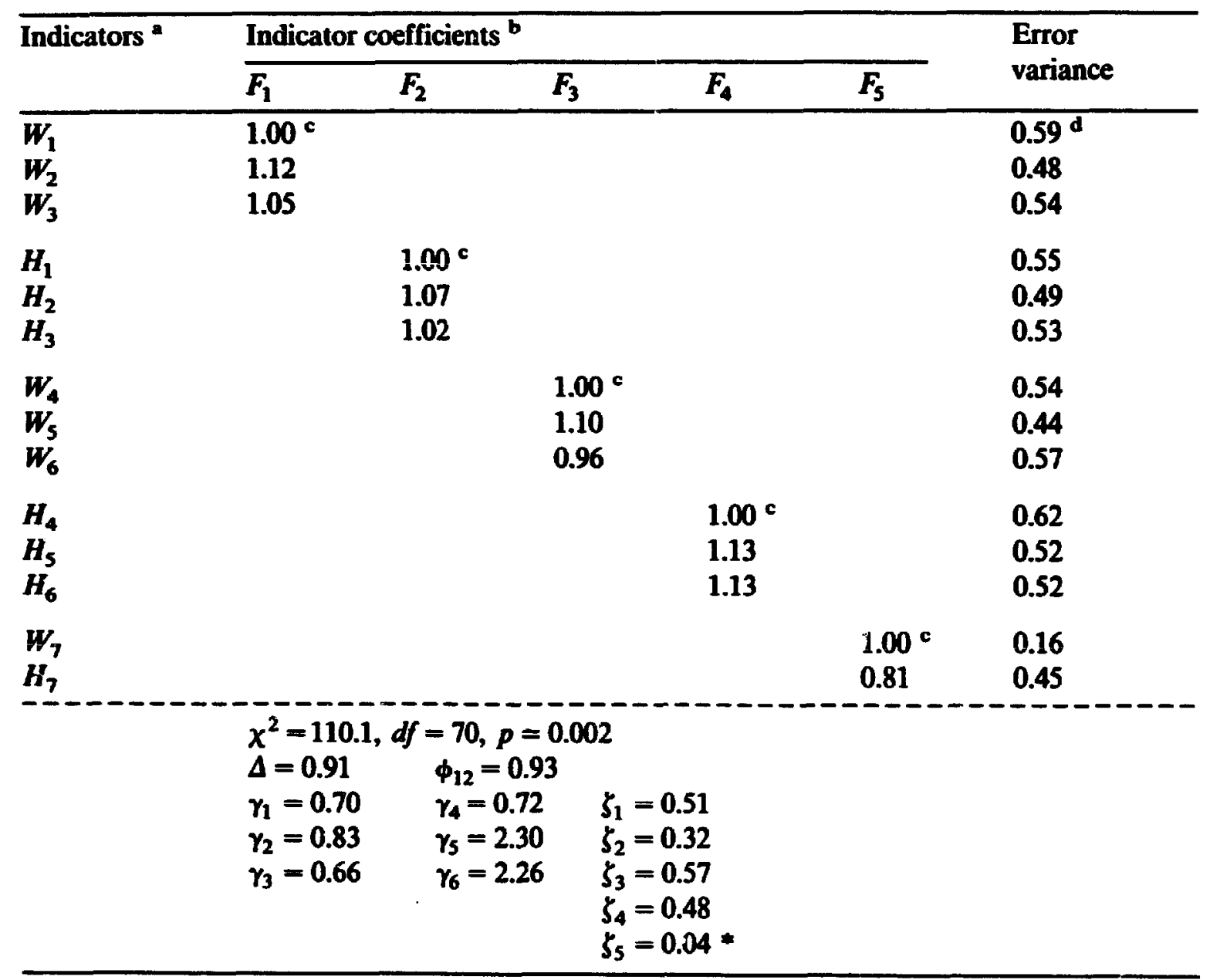

a $W_{i}, H_{i}$ defined in text and in fig. 3.

b $F_{j}$ defined in text.

c Fixed parameter.

d All parameters for this model were at lecst twice their respective standard errors except as noted with asterisk.

couple utilities on expectations reveal high standard errors. This is most likely a consequence of multicollinearity between the two couple constructs. As a matter of fact, the two constructs correlate very highly $\left(\phi_{12}=0.93\right)$, with the correlation failing within one standard error of 1.00 (i.e. $=0.08$ ). Therefore, the two couple constructs do not demonstrate discriminant validity, and the model of fig. 4 becomes the focus of inquiry.

Table 3 presents the findings for the model of fig. 4 . As can be seen in the top of the table, all measurement parameters are statistically 
Table 3

Standardized parameter estimates, goodness-of-fit, and incremental fit measures for the model of fig. 4.

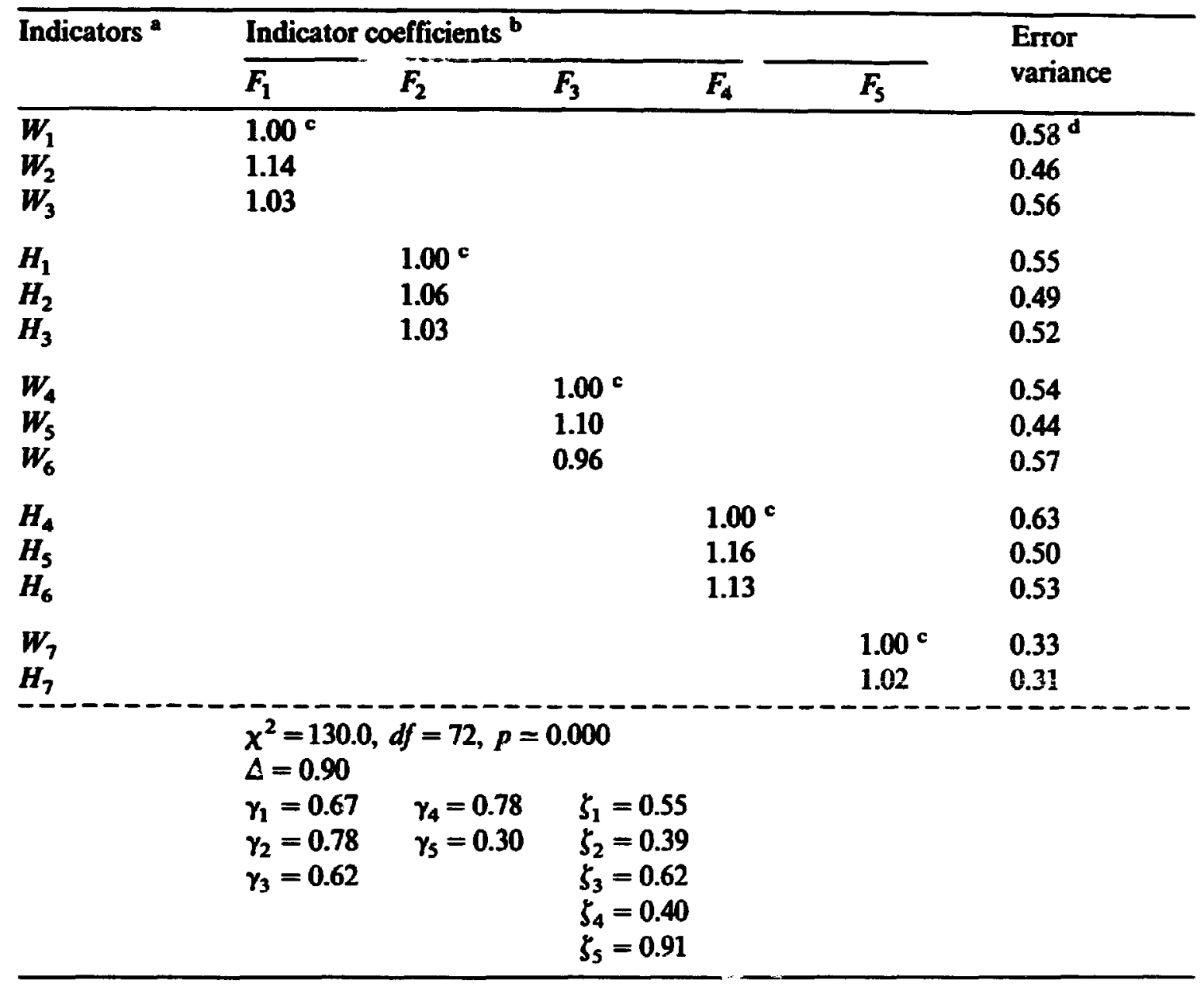

a $W_{i}, H_{i}$ defined in text and in fig. 4.

b $F_{j}$ defined in text.

c Fixed parameter.

d All parameters for this model were at least twice their respective standard errors.

significant and random errors are low to moderate in magnitude. Further, although the chi-square measure $\left(\chi^{2}=130.0, d f=72, p=\right.$ $0.000)$ indicates a borderline fit, the incremental fit index $(\Delta=0.90)$ shows that the model accounts for a high proportion of variance as a practical matter.

Turning next to the structural parameters (bottom of table 3), we see that a single, overall couple utility for children is supported. The wife's and husband's economic and emotional utilities serve as direct indicators of the couple utility construct. With the contribution of the wife's economic utility standardized at 1.00 , we see that the relative contribu- 
tions of the husband's economic, wife's emotional, and husband's emotional utilities are $1.16,0.92$, and 1.16 , respectively (see $\gamma_{1}-\gamma_{4}$ ). This points to a more-or-less equal contribution, on average, across spouses and types of utility.

As a final analysis, correlated errors reflecting method or other biases were investigated within the context of the model of fig. 4. This was done for comparison purposes to the models investigated by Thomson (1983) and to discover if a satisfactory chi-square measure wolid result with a small number of correlated errors. The findings for the appropriate modification of fig. 4 yielded: $\chi^{2}=82.82, d f=68$, and $p=0.107$, an acceptable solution. Four correlated errors were necessary: $\psi_{41}=-0.13(0.05), \psi_{s 3}=0.19(0.05), r_{\varepsilon 2, \varepsilon 8}=0.10(0.04), r_{\varepsilon 13, \varepsilon 5}=$ $-0.06(0.03)$, where $\psi_{i, j}$ is the covariance among the first-order factors, $r_{\varepsilon i, \varepsilon j}$ is the correlation among errors in measurements and standard errors are in parentheses. It should be noted that the four correlated errors are relatively sinall in relation to the number of factors and measurements. Moreover, the magnitudes of the errors are very small in both an absolute sense and in relation to other measurement parameters in the model. Nevertheless, it is difficult to suggest a rationale, even ex post, for these correlations. It should be noted that the key structural parameters of the model (i.e., $\gamma_{1}-\gamma_{5}$ ) dici not change significantly from the findings for the model of fig. 4 . Thus, the substantive conclusions remain similar to that arising for the model centaining no correlated errors.

\section{Discussion}

Thomson's (1983) two models for explaining couple's expectations for another child represent the decision process as either a strictly individual level phenomenon or a totally shared one. That is, her wife-husband model hypothesizes that expectations are direct, independent functions of wife's economic, wife's emotional, husband's economic, and husband's emotional utility of children; whereas her couple model asserts that expectations are determined by a couple economic and a couple eniotional construct. As we argued earlier, the former model exhibits conceptual ambiguities and methodological shortcomings, and showed anomalous findings. The latter model is unduly restrictive in that it fails to allow for multidimensional reactions. 
We hypothesize that a third possibility exists: namely, utility consists of components unique to each spouse and a component shared by the spouses. In addition, distinct economic and emotional utilities are permitted. Although we found that a single, shared utility construct was sufficient to capturs the joint tastes of the couples surveyed in this study (see fig. 4), we leave open the possibility that multiple, shared utility constructs can function for some people in certain contexts (see fig. 3). For instance, multiple, shared utility constructs might exit for different types or subsets of meaningful attributes or consequences of having children. In any case, our representation of tastes for another child partitions the individual psychological reactions of the spouses into (a) factors representing utility unique to the husband and unique to the wife, (b) factors of shared utility between the spouses, and (c) random error.

The results showed (see fig. 4 and table 3 ) that expectations are a direct function of the couple's utility when the latter is construed as a second-order latent variable indicated by the wife's and husband's economic and emotional utilities which, in turn, are first-order latent variables. This formulation may seem odd in that common sense implies that the couple's utility should be a function of the individual spouse's utilities. However, the apparent counterintuitive formulation follows the convention of later ${ }^{+}$variable models and can be reinterpreted in a straightforward manner.

The formulation shown in fig. 4 and put forth in eqs. (1)-(3) can be seen to follow the convention established in classical test-score theory (e.g., Lord and Novick 1968). That is, an indicator is hypothesized to be a function of a latent variable plus an error term rather than the latent variable specified to be a function of its indicator. The arrow indicated by $\gamma_{5}$ in fig. 4 has a different interpretation than the remaining arrows: it is a functional or causal relation, whereas the other arrows are assumed to be reflections of correspondence rule relations (e.g., Bagozzi 1980, 1984). The former relation $\left(\gamma_{5}\right)$ represents the key causal hypothesis. The latter relations represent measurement hypotheses at either relatively concrete $\left(\lambda_{1}-\lambda_{13}\right)$ or ahstract $\left(\gamma_{1}-\gamma_{4}\right)$ levels of discourse. The underlying assumption is that the couple's utility, a social construct, is indicated by individual spouse utilities which are, in turn, psychological constructs.

It might be meaningful to model the couple's utility as a direct function of the individual utilities. But it is important to recognize that 
a different theory of aggregation is required to do so. Moreover, separais measures of couple's utility would be needed to operationalize the model because, with the arrowheads reversed for $\gamma_{1}-\gamma_{4}$, the model is not identified as it stands. Finally, granting that a model with arrowheads $\gamma_{1}-\gamma_{4}$ reversed is meaningful, it is likely as a practical matter that estination problems would arise, since high intercorrelations among individual utilities (a likely occurrence) might lead to problems of multicollinearity.

The true-score like formulation shown in fig. 4 permits one to determine the common utility as a direct effect $\left(\gamma_{5}\right)$ and to interpret the individual contributions of husband and wife as indirect effects $\left(\gamma_{1}-\gamma_{4}\right)$. We leave open the possibility that another methodology may be used to arrive at a somewhat different conceptualization of the indirect effects.

Overall, the findings in the present study suggest that the utility for another child is, in part, an individual experience and, in part, a joint experience of husband and wife. Each spouse does have a separate utility for children. Yet, the couple, at least temporarily, reaches a shared understanding and mutual decision for the family unit as a whole.

The process appears to entail a social exchange whereby individual needs are resolved through give-and-take and the application of persuasion and ir Tuence. This is not to say that conflicts of interest or power disparities do not occur. Indeed, the theory developed horein allows for these to exist and to influence decisions, as reflected through imbalances in role relationships and other social processes.

By way of interpretation, we feel that our tests of hypotheses in this article can be categorized as a primitive interaction theory in the sense depicted in fig. 2. It is an interaction theory in the sense of attempting to represent social processes (i.e., shared utility) as an intervening variable between psychological processes and family decisions and outcomes. We recognize, as a reviewer pointed out, that our particular analyses are not at all dynamic and that outcome and process theories might be combined in a complementary manner. Future enquiry should address the interpersonal processes implied by fig. 2 and explain actual behavior and outcomes (c.f., Bagozzi and Van Loo 1987; and Van Loo and Bagozzi 1984). 


\section{References}

Bagozzi, R.P., 1980. Causal models in marketing. New York: Wiley.

Bagozzi, R.P., 1984. A prospectus for theory construction in marketing. Journal of Marketing 48, 11-29.

Bagozzi, R.P., 1985. Expectancy-value attitude models: an analysis of critical theoretical issues. International Journal of Research in Marketing 2, 43-60.

Bagozai, R.P. and M.F. Van Loo, 1978. Toward a general theory of fertility: a causal modeling approach. Demography 15, 301-320.

Bagozai, R.P. and M.F. Van Loo, 1980. 'Decision-making and fertility: a theory of exchange in the family'. In: T.K. Burch (ed.), Demographic behavior: interdisciplinary perspectives on decision-making. (American Association for the Advancement of Science Selected Symposium 45.) Boulder, CO: Westview. pp. 91-124.

Bagozzi, R.P. and M.F. Van Loo, 1982. Fertility, labor force participation and tastes: an economic psychology perspective. Journal of Economic Psychology 2, 247-285.

Bagozzi, R.P. and M.F. Van Loo, 1987. An investigation of the relationship between work and family size decisions over time. Unpublished working paper.

Beckman, LJJ., 1978. The relative rewards and costs of parenthood and employment for employed women. Psychology and Women Quarterly 2, 215-234.

Beckman, L.J., 1979. Fertility preferences and social exchange theory. Journal of Applied Social Psychology 9, 147-169.

Beckman, L.J., R. Dizenberg, A.B. Forsythe and T. Day, 1983. A theoretical analysis of antecedents of young couples' fertility decisions and outcomes. Demography 20, 519-533.

Bentler, P.M. and D.G. Bonett, 1980. Significance tests and goodness of fit in the analysis of covariance structures. Psychological Bulletin 8, 588-606.

Bulatao, R.A., 1976. 'Values, attitudes and the desire for children'. In: R.A. Bulatao (ed.), Philippine population research: papers and proceedings of an experts' meeting. Makati: Population Center Foundation. pp. 275-305.

Campbell, D.T. and D.W. Fiske, 1959. Convergent and discriminant validation by the multitrait-multimethod matrix. Psychological Bulletin 56, 81-105.

Davidson, A.R. and J.J. Jaccard, 1975. Population psychology: a new look at an old problem. Journal of Personality and Social Psychology 31, 1073-1082.

Fishbein, M., 1972. Toward an understanding of family planning behaviors. Journal of Applied Social Psychology 2, 214-227.

Fleisher, B.M. and G.F. Rhodes, Jr., 1979. Fertility, women's wage rates, and labor supply. American Economic Review 69, 14-24.

Harre, R. and P.F. Secord, 1973. The explanation of social behavior. Totowa, NJ: Littlefield, Adams.

Hoffman, L.W. and M.L. Hoffman, 1973. 'The value of children to parents'. In: J.T. Fawcett (ed.), Psychological perspectives on population. New York: Basic Books. pp. 19-76.

Hoffman, L.W., A. Thomton and J.D. Manis, 1978. The value of children to parents in the United States. Journal of Population 1, 91-132.

Hollerbach, P.E., 1980. Power in families, communicai in and fertility decision-making. Population and Environment: Behavioral and Social Issues 3, 146-173.

Jöreskog, K.G. and D. Sörbom, 1978. LISREL IV: a general computer program for estimation of a linear structu-al equation system by maximum likelihood methods. Chicago, IL: National Educational Resources.

Keat, T. and J. Urry, 1983. Social theory as science. (Rev. ed.) London: Routledge and Kegan Paul. 
Long, J.S., 1983. Covariance structure moc els: an introduction to LISREL. Beverly Hills, CA: Sage.

Lord, F.M. and M.R. Novick, 1968. Statistical theories of mental test scores. Reading, MA: Addison-Wesley.

Manicas, P.T. and P.F. Secord, 1983. Implications for psychology of the new philosophy of science. American Psychologist 38, 399-413.

Seidler, J., 1974. On using informants: a technique for collecting quantitative data and controlling for measurement error in organization analysis. American Sociological Review 39, 816-831.

Smith-Lovin, L. and A.R. Tickamyer, 1978. Nonrecursive models of labor force participation, fertility behavior, and sex role attitudes. American Sociological Review 43, 541-557.

Thomson, E., 1983. Individual and couple utility of children. Demography 20, 507-518.

Van Loo, M.F. and R.P. Bagozzi, 1984. Labor force participation and fertility: a social analysis of their antecedents and simultaneity. Human Relations 37, 941-967.

Vinokur-Kaplan, D., 1978. To have-or-not have another child: family planning attitudes, intentions, and behavior. Journal of Applied Social Psychology 8, 29-46.

Waite, L.J. and R.M. Stolzenberg, 1976. Intended childbearing and labor force participation of young women: insights from nonrecursive models. American Sociological Review 41, 235-252.

Webster, M., 1973. Psychological reductionism, methodological individualism, and large scale problems. American Sociological Review 38, 258-273.

Willis, R.J., 1973. A new approach to the economic theory of fertility behavior. Journal of Political Economy 81, S14-S64. 